\title{
Aberrant methylation of microRNA-34b/c is a predictive marker of metachronous gastric cancer risk
}

\author{
Ryo Suzuki • Eiichiro Yamamoto • Masanori Nojima - Reo Maruyama - Hiro-o Yamano $\cdot$ Kenjiro Yoshikawa \\ Tomoaki Kimura $\cdot$ Taku Harada $\cdot$ Masami Ashida $\cdot$ Takeshi Niinuma $\cdot$ Akiko Sato $\cdot$ Katsuhiko Nosho • \\ Hiroyuki Yamamoto $\cdot$ Masahiro Kai $\cdot$ Tamotsu Sugai $\cdot$ Kohzoh Imai $\cdot$ Hiromu Suzuki $\cdot$ Yasuhisa Shinomura
}

Received: 8 April 2013/Accepted: 25 July 2013/Published online: 13 August 2013

(C) The Author(s) 2013. This article is published with open access at Springerlink.com

\begin{abstract}
Background Metachronous gastric cancer (GC) can develop after endoscopic resection of GC and cannot be predicted based on clinical signature. Aberrant DNA methylation in noncancerous gastric mucosa is strongly implicated in gastric carcinogenesis and could be a useful biomarker of GC risk. We evaluated the clinical utility of DNA methylation as a biomarker of metachronous GC risk. Method We carried out scheduled follow-up endoscopy in 129 patients after curative endoscopic resection of GC. Biopsy specimens were collected from noncancerous mucosa in the gastric antrum and body, after which quantitative methylation analysis of $m i R-34 b / c, S F R P 1$, SFRP2, SFRP5, DKK2 and DKK3 was carried out using bisulfite pyrosequencing. The utility of the methylation for predicting the risk of metachronous GC development was
\end{abstract}

R. Suzuki, E. Yamamoto contributed equally to this work.

Electronic supplementary material The online version of this article (doi:10.1007/s00535-013-0861-7) contains supplementary material, which is available to authorized users.

R. Suzuki $\cdot$ E. Yamamoto $\cdot$ R. Maruyama $\cdot$ T. Niinuma

K. Nosho $\cdot$ H. Yamamoto $\cdot$ Y. Shinomura $(\bowtie)$

Department of Gastroenterology, Rheumatology and Clinical

Immunology, Sapporo Medical University, S1, W16, Chuo-Ku,

Sapporo 060-8543, Japan

e-mail: shinomura@sapmed.ac.jp

E. Yamamoto $\cdot$ R. Maruyama $\cdot$ T. Harada $\cdot$ M. Ashida .

T. Niinuma · A. Sato · M. Kai · H. Suzuki $(\bowtie)$

Department of Molecular Biology, Sapporo Medical University,

S1, W17, Chuo-Ku, Sapporo 060-8556, Japan

e-mail: hsuzuki@sapmed.ac.jp

M. Nojima

The Advanced Clinical Research Center, The Institute of

Medical Science, The University of Tokyo, Tokyo, Japan assessed using Kaplan-Meier and Cox proportional hazards model analyses.

Results During the follow-up period, 17 patients (13\%) developed metachronous GCs. The cumulative incidence of metachronous GC was significantly higher among patients with elevated $m i R-34 b / c, S F R P 2$ and $D K K 2$ methylation in their gastric body. MiR-34b/c showed the strongest association with the risk of metachronous GC, and the cumulative incidence of metachronous GC was much higher in the high-miR-34b/c-methylation group than the low-methylation group. Multivariate analysis adjusted for age, sex, H. pylori status and pathological findings showed $m i R-34 b / c$ methylation in gastric body to be an independent predictor of metachronous GC risk.

Conclusion Our results suggest that methylation of $\mathrm{miR}$ $34 \mathrm{~b} / \mathrm{c}$ in the mucosa of the noncancerous gastric body may be a useful biomarker for predicting the risk of metachronous GC.

Keywords Metachronous gastric cancer - DNA methylation - Biomarker - Risk assessment

H. Yamano $\cdot$ K. Yoshikawa $\cdot$ T. Kimura

Department of Gastroenterology, Akita Red Cross Hospital, Akita, Japan

T. Sugai

Department of Pathology, Iwate Medical University, Morioka, Japan

K. Imai

The Advanced Clinical Research Center, The Institute of Medical Science, The University of Tokyo, Tokyo, Japan 


\section{Introduction}

Gastric cancer (GC) is a major cause of cancer mortality worldwide, and its early detection and endoscopic resection are essential for reducing the incidences of invasion and metastasis and improving survival. Endoscopic submucosal dissection (ESD) enables en bloc and histologically complete resection with no restriction on lesion size [1-4]. Although this approach minimizes the recurrence rate and preserves the entire stomach and the patient's quality of life, metachronous GC develops in the remnant stomach in about $10-20 \%$ of patients after curative ESD [5-7]. Consequently, assessing the risk of metachronous GC after ESD is extremely important for early detection of subsequent $\mathrm{GC}$ and reduction of mortality.

Helicobacter pylori (H. pylori) infection plays an important role in gastric carcinogenesis [8]. GCs are thought to arise from $H$. pylori-related gastritis, and the severe mucosal atrophy and intestinal metaplasia it causes are associated with the development of metachronous GC. Correspondingly, eradicating $H$. pylori after ESD reduces the likelihood of metachronous GC [9]. However, the individuals at high risk of developing metachronous GC cannot be predicted based on clinicopathological findings, including $H$. pylori status. Thus, identification of a molecular marker useful for predicting the risk of metachronous GC would be highly desirable.

Epigenetic alterations such as DNA methylation play a key role during gastric carcinogenesis [10, 11]. For example, DNA methylation is known to silence a variety of genes involved in cell-cycle control, apoptosis, cell signaling and DNA repair in GC [10, 12]. Earlier reports have shown that $H$. pylori infection induces methylation of tumor suppressor and other tumor-related genes in the noncancerous gastric mucosa, suggesting aberrant DNA methylation is an early event during gastric carcinogenesis [13]. We and others previously demonstrated that the level of DNA methylation of tumor suppressor genes is increased in cases of gastritis that are at epidemiologically high risk for developing GC and in the background noncancerous gastric mucosa in GC [14-16]. In addition, we previously reported that the level of $m i R-34 \mathrm{~b} / \mathrm{c}$ gene methylation is significantly higher in noncancerous gastric mucosa from patients with multiple GCs than in those with a single GC or in $H$. pylori-positive healthy individuals [17]. These results suggest DNA methylation in noncancerous gastric mucosa may be a useful biomarker for evaluating the risk of metachronous GC after ESD.

Our aim in the present study was to assess the clinical utility of DNA methylation in the noncancerous gastric mucosa as a marker of the risk of metachronous GC. Our approach was to perform a prospective study in a cohort of GC patients who underwent curative ESD.

\section{Materials and methods}

Study population

This study included 129 patients who received curative endoscopic resection of early GC at Akita Red Cross Hospital between May 2007 and May 2011. Surveillance endoscopy was regularly performed every 6-12 months. At the time of enrollment (first detection of GC), biopsy specimens of noncancerous gastric mucosa were obtained from the gastric body and antrum for histological examination and extraction of genomic DNA. After enrollment, patients were hospitalized and their tumors were treated with ESD. The follow-up period was defined as being between the first biopsy and the detection of metachronous GC, the censoring of the patients or the end of this study. The updated Sydney system was used to estimate the degree of gastritis [18]. Genomic DNA was extracted using the standard phenol-chloroform procedure. H. pylori infection was assessed using the rapid urease test, the serum antibody test and the urea breath test. If any one of these assays was positive, the patients were considered to be $H$. pylori-positive. All individuals had no history of $H$. pylori eradication therapy. After endoscopic treatment, 49 $H$. pylori-positive GC patients received $H$. pylori eradication treatment, and successful eradication was confirmed. Metachronous GC was defined as new GC developing after curative resection of GC. Written informed consent was obtained from all patients before collection of the specimens. Approval of this study was obtained from the Institutional Review Board of Akita Red Cross Hospital and Sapporo Medical University.

\section{Methylation analysis by bisulfite-pyrosequencing}

Genomic DNA $(1 \mu \mathrm{g})$ was modified with sodium bisulfite using an EpiTect Bisulfite Kit (QIAGEN, Hilden, Germany), after which bisulfite sequencing and pyrosequencing were carried out as described previously [19]. For bisulfite pyrosequencing, the biotinylated PCR product was purified, made single-stranded and used as the template in a pyrosequencing reaction run according to the manufacturer's instructions. The pyrosequencing reaction was carried out using a PSQ96 system with a PyroGold reagent Kit (QIAGEN), and the results were analyzed using Q-CpG software (QIAGEN). Sequence information for primers is shown in Supplementary Table 1.

Statistical analysis

The cumulative incidences of metachronous GC were calculated using the Kaplan-Meier method. Comparisons between groups were made using the log-rank test. 
Univariate and multivariate analyses were performed using Cox proportional hazard models to assess the risk factors for metachronous GC. Fisher's exact test or Pearsons' chisquared test was used for analysis of categorical data. Values of $p<0.05$ (two-sided) were considered statistically significant. All statistical analyses were performed using SPSS Statistics 18 (IBM Corporation, Somers, NY, USA) and JMP ver. 10 (SAS Institute Inc., Cary, NC, USA).

\section{Results}

Patient characteristics

The profiles of the study participants are shown in Fig. 1. After excluding patients who were lost to follow-up or died of extragastric disease, $129 \mathrm{GC}$ patients were enrolled in the study. The median follow-up period for the $129 \mathrm{GC}$ patients was 1.5 (range 0.1-6.1) years. A total of 86 patients exhibited $H$. pylori infection; of those, 51 underwent eradication therapy after endoscopic resection of their GC, and the H. pylori was successfully eradicated in 49 (96\%). Twenty-six patients were $H$. pylori-negative, although the majority of those were presumed to have been infected in the past, as they exhibited intestinal metaplasia or gastric mucosal atrophy (data not shown). H. pylori status was not available for 17 patients. During the followup period, 17 patients $(13 \%)$ developed metachronous GCs. This included $12 \mathrm{H}$. pylori-positive patients, among whom five were successfully treated for $H$. pylori after endoscopic resection of their GC (Table 1).

Association between $m i R-34 b / c$ methylation and the occurrence of metachronous GC

The primary endpoint of this study was the occurrence of metachronous GC during the follow-up period. At the time

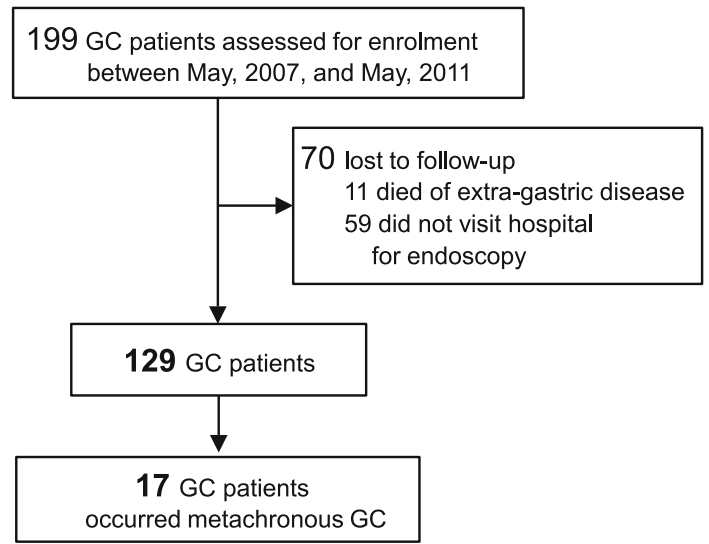

Fig. 1 Profiles of participants in this study each patient entered the study, biopsy specimens of noncancerous gastric mucosa were collected from the antrum and body of the stomach, after which methylation levels of $m i R-34 b / c, S F R P 1, S F R P 2, S F R P 5, D K K 2$ and DKK3 were determined using quantitative bisulfite pyrosequencing. These six genes are known to be frequently methylated in H. pylori-related gastritis as well as in GC [17, 20, 21]. Based on the results, patients were categorized into a highmethylation or low-methylation group, relative to the median baseline methylation levels in the gastric body and antrum among the $129 \mathrm{GC}$ patients. Thereafter, we assessed the correlations between methylation of the respective genes and the incidence of metachronous GC. Using a univariate Cox proportional hazards model, the greatest hazard ratio (HR) was obtained for patients showing higher levels of $m i R-34 b / c$ methylation in the gastric body when a cutoff of $18.6 \%$ was employed (HR, 10.01; $95 \% \mathrm{CI}$, 2.26-44.23, $p=0.002$ ). Similarly, we found an elevated risk of metachronous GC in patients with higher levels of SFRP2 (cutoff, $43.3 \%$; HR, 3.33; $95 \%$ CI, 1.08-10.25, $p=0.02$ ) and $D K K 2$ (cutoff, $16.9 \%$; HR, 3.66; $95 \% \mathrm{CI}$, $1.19-11.25, p=0.01$ ) methylation in the gastric body (Fig. 2a). In addition, Kaplan-Meier analysis revealed that greater methylation of these three genes in the gastric body was significantly associated with shorter metachronous GC-free survival $(m i R-34 b / c, \quad p \leq 0.001 ; \quad S F R P 2$, $p=0.025$; DKK2, $p=0.015$ by log-lank test) (Fig. $2 \mathrm{~b}$, Supplementary Figure 1). By contrast, we found no significant correlation between the incidence of metachronous GC and methylation in the antral mucosa (Supplementary Figure 2).

The results summarized above prompted us to select $m i R-34 b / c$ methylation in the gastric body for further analysis (Supplementary Figure 3). The 2-year cumulative incidence of metachronous GC in the high-methylation group ( $\geq 18.6 \%$ ) was $30.4 \%$ (95\% CI, 15.9-44.9), while that for the low-methylation group $(\leq 18.6 \%)$ was only $3.8 \%$ (95\% CI, 0-12.6) (Table 2). When we then divided the $129 \mathrm{GC}$ patients into four quartiles based on the level of $m i R-34 b / c$ methylation in the gastric body, we found that the cumulative incidence of metachronous GC significantly differed among the four groups ( $p \leq 0.001$ by log-lank test) (Supplementary Figure 4). These results suggest that levels of $m i R-34 b / c$ methylation in the gastric body mucosa could be a predictive marker of the risk of metachronous GC.

Clinicopathological features of the high and low methylation groups

The associations between the clinicopathological features and $m i R-34 b / c$ methylation are summarized in Table 3. Among the GC patients, $m i R-34 b / c$ methylation was associated with older age and a greater degree of 
Table 1 Clinicopathological features of the patients enrolled in this study

\begin{tabular}{|c|c|c|c|c|}
\hline & \multirow[t]{2}{*}{ Total $(N=129)$} & \multicolumn{2}{|c|}{ Incidence of metachronous GC } & \multirow[t]{2}{*}{$p$ value } \\
\hline & & No $(N=112)$ & Yes $(N=17)$ & \\
\hline Age (means) & $69.2(35-89)$ & $68.6(35-86)$ & $72.8(56-89)$ & 0.104 \\
\hline \multicolumn{5}{|l|}{ Sex } \\
\hline Male & $92(71.3 \%)$ & $77(68.7 \%)$ & $15(88.2 \%)$ & \multirow[t]{2}{*}{0.149} \\
\hline Female & $37(28.6 \%)$ & $35(31.2 \%)$ & $2(11.7 \%)$ & \\
\hline Follow-up years (means) & $1.5(0.1-6.1)$ & $1.4(0.1-6.1)$ & $2.6(0.3-6.1)$ & 0.039 \\
\hline \multicolumn{5}{|l|}{ H. pylori infection } \\
\hline Positive & $86(66.6 \%)$ & $74(66.0 \%)$ & $12(70.5 \%)$ & \multirow[t]{3}{*}{0.538} \\
\hline Negative & $26(20.1 \%)$ & $21(18.7 \%)$ & $5(29.4 \%)$ & \\
\hline Unknown & $17(13.1 \%)$ & $17(15.1 \%)$ & $0(0.0 \%)$ & \\
\hline \multicolumn{5}{|c|}{ Pathological findings of noncancerous gastric mucosa $(N=122)$} \\
\hline \multicolumn{5}{|l|}{ Antrum } \\
\hline \multicolumn{5}{|l|}{ Inflammation } \\
\hline Severe-moderate & $23(18.8 \%)$ & $22(20.7 \%)$ & $1(6.2 \%)$ & \multirow[t]{2}{*}{0.301} \\
\hline Mild-none & $99(81.1 \%)$ & $84(79.2 \%)$ & $15(93.7 \%)$ & \\
\hline \multicolumn{5}{|l|}{ Activity } \\
\hline Severe-moderate & $19(15.5 \%)$ & $18(16.9 \%)$ & $1(6.2 \%)$ & \multirow[t]{2}{*}{0.462} \\
\hline Mild-none & $103(84.4 \%)$ & $88(83.0 \%)$ & $15(93.7 \%)$ & \\
\hline \multicolumn{5}{|l|}{ Atrophy } \\
\hline Severe-moderate & $101(82.7 \%)$ & $87(82.0 \%)$ & $14(87.5 \%)$ & \multirow[t]{2}{*}{0.736} \\
\hline Mild-none & $21(17.2 \%)$ & $19(17.9 \%)$ & $2(12.5 \%)$ & \\
\hline \multicolumn{5}{|l|}{ Metaplasia } \\
\hline Severe-moderate & $71(58.2 \%)$ & $60(56.6 \%)$ & $11(68.7 \%)$ & \multirow[t]{2}{*}{0.424} \\
\hline Mild-none & $51(41.8 \%)$ & $46(43.4 \%)$ & $5(31.2 \%)$ & \\
\hline \multicolumn{5}{|l|}{ Body } \\
\hline \multicolumn{5}{|l|}{ Inflammation } \\
\hline Severe-moderate & $78(63.9 \%)$ & $66(62.2 \%)$ & $12(75.0 \%)$ & \multirow[t]{2}{*}{0.409} \\
\hline Mild-none & $44(36.0 \%)$ & $40(37.7 \%)$ & $4(25.0 \%)$ & \\
\hline \multicolumn{5}{|l|}{ Activity } \\
\hline Severe-moderate & $68(55.7 \%)$ & $60(56.6 \%)$ & $8(50.0 \%)$ & \multirow[t]{2}{*}{0.788} \\
\hline Mild-none & $54(44.2 \%)$ & $46(43.4 \%)$ & $8(50.0 \%)$ & \\
\hline \multicolumn{5}{|l|}{ Atrophy } \\
\hline Severe-moderate & $69(56.5 \%)$ & $56(52.8 \%)$ & $13(81.2 \%)$ & \multirow[t]{2}{*}{0.056} \\
\hline Mild-none & $53(43.4 \%)$ & $50(47.1 \%)$ & $3(18.7 \%)$ & \\
\hline \multicolumn{5}{|l|}{ Metaplasia } \\
\hline Severe-moderate & $30(24.5 \%)$ & $24(22.6 \%)$ & $6(37.5 \%)$ & \multirow[t]{2}{*}{0.219} \\
\hline Mild-none & $92(75.4 \%)$ & $82(77.3 \%)$ & $10(62.5 \%)$ & \\
\hline
\end{tabular}

inflammation, activity, atrophy and metaplasia in the gastric body (Table 3). By contrast, no significant differences were found with respect to sex, $H$. pylori infection or pathological findings in the antral mucosa (Table 3).

Evaluating the risk of metachronous GC with clinical predictors

We next used univariate analysis and multivariate Cox proportional-hazards analysis to evaluate the utility of the $m i R$ $34 \mathrm{~b} / \mathrm{c}$ methylation level in the mucosa of the noncancerous gastric body as a predictive marker of metachronous GC risk. In the univariate analysis, $m i R-34 b / c$ methylation and mucosal atrophy in the gastric body were significantly associated with the occurrence of metachronous GC (Table 4). On the other hand, inflammation, activity and metaplasia were not significant predictors of the occurrence of metachronous GC. In a multivariate analysis adjusted for $m i R-34 b / c$ methylation, age, sex, $H$. pylori status and pathological findings (inflammation, activity, atrophy and metaplasia), $m i R-34 b / c$ methylation and inflammation were independently associated with metachronous GC (Table 4). 
Fig. 2 Associations between DNA methylation and metachronous GC risk. a Forest plot showing hazard ratios (closed circles) for developing metachronous GC and $95 \%$ confidence intervals (bar lines). Univariate Cox proportional hazards model analysis was performed to assess the correlations between methylation of the six indicated genes and the incidence of metachronous GC. b KaplanMeier analysis of the effect of $m i R-34 b / c$ methylation in the gastric body on metachronous GC-free survival $(n=129)$
A

Hazard Ratio $(95 \% \mathrm{Cl})$ p-value cutoff $(\%)$
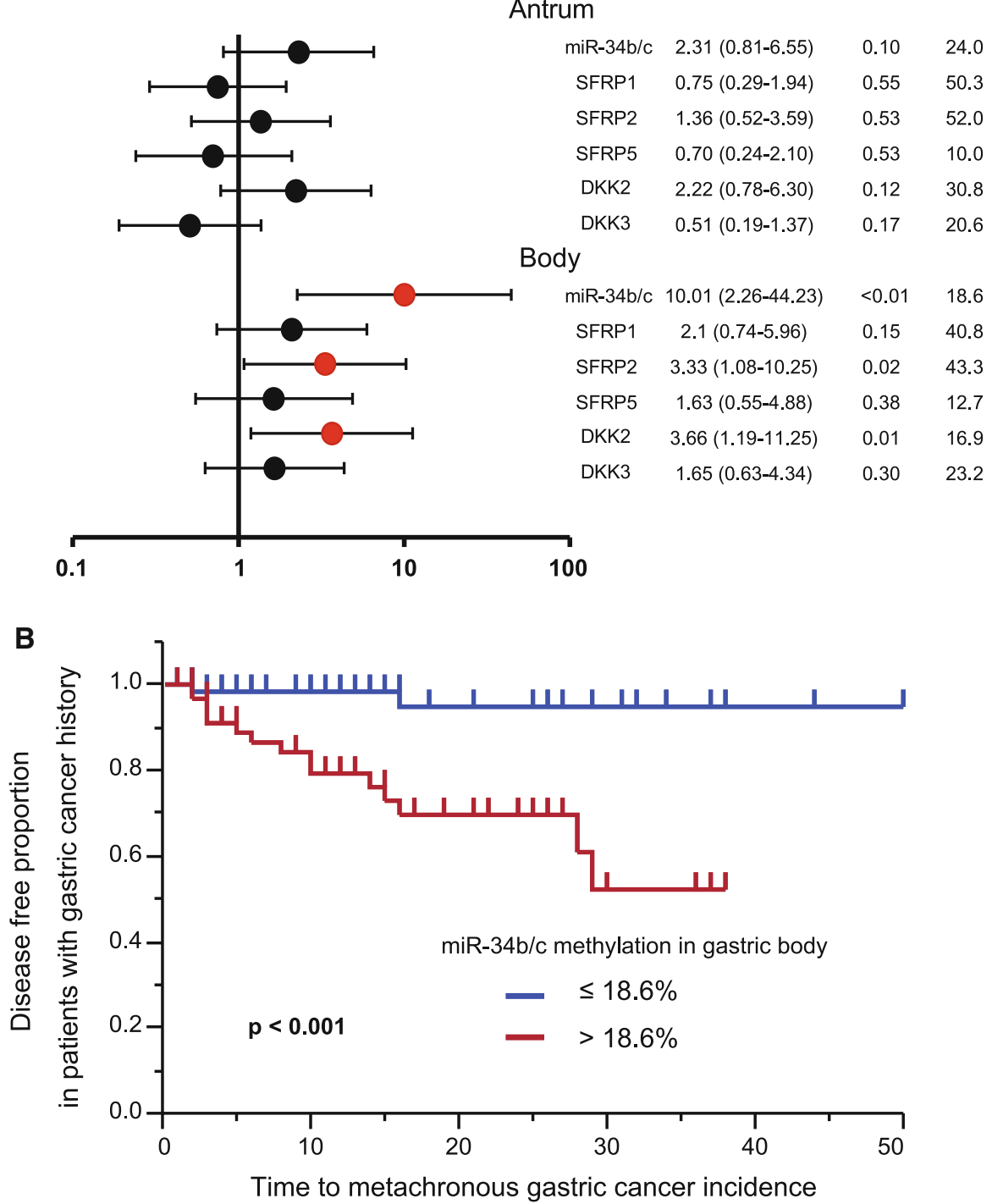

(month)
Table 2 Methylation of $m i R$ $34 \mathrm{~b} / \mathrm{c}$ in noncancerous gastric body mucosa and its association with metachronous gastric cancer

$C I$ confidence interval, $M G C$ metachronous gastric cancer

\begin{tabular}{|c|c|c|c|c|c|c|c|}
\hline \multirow[t]{2}{*}{ Methylation (\%) } & \multirow[t]{2}{*}{ Periods } & \multirow[t]{2}{*}{ Total } & \multirow[t]{2}{*}{ Non MGC } & \multirow[t]{2}{*}{ MGC } & \multirow[t]{2}{*}{ Incidence rate $(\%)$} & \multicolumn{2}{|l|}{$95 \% \mathrm{CI}$} \\
\hline & & & & & & Lower $(\%)$ & Upper (\%) \\
\hline \multirow[t]{3}{*}{$\leq 18.6$} & 1 Year & 65 & 64 & 1 & 1.7 & 0.0 & 5.0 \\
\hline & 2 Years & 31 & 30 & 1 & 3.8 & 0.0 & 12.6 \\
\hline & 3 Years & 24 & 24 & 0 & 3.8 & 0.0 & 12.6 \\
\hline \multirow[t]{3}{*}{$>18.6$} & 1 Year & 64 & 58 & 10 & 20.7 & 9.1 & 32.3 \\
\hline & 2 Years & 24 & 21 & 3 & 30.4 & 15.9 & 44.9 \\
\hline & 3 Years & 12 & 10 & 2 & 47.8 & 24.3 & 71.3 \\
\hline
\end{tabular}

MiR-34b/c methylation, $H$. pylori status and the incidence of metachronous GC

Recent studies demonstrated that eradicating $H$. pylori after endoscopic resection of early GC reduces the risk of metachronous GC [9]. To assess the relationship between $m i R-34 b / c$ methylation and $H$. pylori status, we compared GC patients who had undergone successful eradication therapy after enrolling in this study $(n=49)$ with those who were $H$. pylori-negative at the start of the study but 
were presumed to have had a past infection $(n=26)$. Kaplan-Meier analysis indicated that $m i R-34 b / c$ methylation in the noncancerous gastric body was significantly associated with a risk of metachronous GC in patients successfully treated for $H$. pylori $(p \leq 0.001)$ (Fig. 3a). Moreover, we also found a significant correlation between methylation and metachronous GC in $H$. pylorinegative patients $(p=0.026)$ (Fig. 3b). These results suggest that $m i R-34 b / c$ methylation in the mucosa of the gastric body may be a useful marker for predicting metachronous GC risk, irrespective of the presence of $H$. pylori.
Table 3 Association between clinicopathological features and $m i R-34 b / c$ methylation

\begin{tabular}{|c|c|c|c|}
\hline & $\begin{array}{l}\text { Methylation-low } \\
(\leq 18.6 \%) \\
N=64\end{array}$ & $\begin{array}{l}\text { Methylation-high } \\
(>18.6 \%) \\
N=65\end{array}$ & $p$ value \\
\hline Age $($ mean $\pm \mathrm{SD})$ & $66.4( \pm 11.2)$ & $72.0( \pm 7.0)$ & 0.004 \\
\hline \multicolumn{4}{|l|}{ Sex } \\
\hline Male & $41(64.0 \%)$ & $51(78.5 \%)$ & \multirow[t]{2}{*}{0.071} \\
\hline Female & $23(35.9 \%)$ & $14(21.5 \%)$ & \\
\hline \multicolumn{4}{|l|}{ H. pylori infection } \\
\hline Positive & $38(59.3 \%)$ & $49(75.4 \%)$ & \multirow[t]{3}{*}{0.152} \\
\hline Negative & $16(25.0 \%)$ & $10(15.4 \%)$ & \\
\hline \multirow[t]{2}{*}{ Unknown } & $10(15.6 \%)$ & $6(9.2 \%)$ & \\
\hline & $\begin{array}{l}\text { Methylation-low } \\
(\leq 18.6 \%) \\
N=62\end{array}$ & $\begin{array}{l}\text { Methylation-high } \\
(>18.6 \%) \\
N=60\end{array}$ & $p$ value \\
\hline \multicolumn{4}{|l|}{$\begin{array}{l}\text { Pathological findings } \\
\text { of noncancerous } \\
\text { gastric mucosa }\end{array}$} \\
\hline \multicolumn{4}{|l|}{ Antrum } \\
\hline \multicolumn{4}{|l|}{ Inflammation } \\
\hline Severe-moderate & $13(21.0 \%)$ & $10(16.7 \%)$ & \multirow[t]{2}{*}{0.544} \\
\hline Mild-none & $49(79.0 \%)$ & $50(83.3 \%)$ & \\
\hline \multicolumn{4}{|l|}{ Activity } \\
\hline Severe-moderate & $12(19.4 \%)$ & $7(11.7 \%)$ & \multirow[t]{2}{*}{0.242} \\
\hline Mild-none & $50(80.6 \%)$ & $53(88.3 \%)$ & \\
\hline \multicolumn{4}{|l|}{ Atrophy } \\
\hline Severe-moderate & $53(85.5 \%)$ & $48(80.0 \%)$ & \multirow[t]{2}{*}{0.423} \\
\hline Mild-none & $9(14.5 \%)$ & $12(20.0 \%)$ & \\
\hline \multicolumn{4}{|l|}{ Metaplasia } \\
\hline Severe-moderate & $39(62.9 \%)$ & $32(53.3 \%)$ & \multirow[t]{2}{*}{0.284} \\
\hline Mild-none & $23(37.1 \%)$ & $28(46.7 \%)$ & \\
\hline \multicolumn{4}{|l|}{ Body } \\
\hline \multicolumn{4}{|l|}{ Inflammation } \\
\hline Severe-moderate & $32(51.6 \%)$ & $46(76.7 \%)$ & \multirow[t]{2}{*}{0.004} \\
\hline Mild-none & $30(48.4 \%)$ & $14(23.3 \%)$ & \\
\hline \multicolumn{4}{|l|}{ Activity } \\
\hline Severe-moderate & $29(46.8 \%)$ & $39(65.0 \%)$ & \multirow[t]{2}{*}{0.043} \\
\hline Mild-none & $33(53.2 \%)$ & $21(35.0 \%)$ & \\
\hline \multicolumn{4}{|l|}{ Atrophy } \\
\hline Severe-moderate & $24(38.7 \%)$ & $45(75.0 \%)$ & \multirow[t]{2}{*}{$<0.001$} \\
\hline Mild-none & $38(61.3 \%)$ & $15(25.0 \%)$ & \\
\hline \multicolumn{4}{|l|}{ Metaplasia } \\
\hline Severe-moderate & $10(16.1 \%)$ & $20(33.3 \%)$ & \multirow[t]{2}{*}{0.027} \\
\hline Mild-none & $52(83.9 \%)$ & $40(66.7 \%)$ & \\
\hline
\end{tabular}


Table 4 Risk factors for development of metachronous GC analyzed by univariate and multivariate analysis

\begin{tabular}{|c|c|c|c|c|c|c|c|c|}
\hline & \multicolumn{4}{|c|}{ Univariate analysis } & \multicolumn{4}{|c|}{ Multivariate analysis } \\
\hline & \multirow[t]{2}{*}{$p$ value } & \multirow[t]{2}{*}{ HR } & \multicolumn{2}{|c|}{$95 \% \mathrm{CI}$} & \multirow[t]{2}{*}{$p$ value } & \multirow[t]{2}{*}{ HR } & \multicolumn{2}{|c|}{$95 \% \mathrm{CI}$} \\
\hline & & & Lower & Upper & & & Lower & Upper \\
\hline$m i R-34 b / c$ methylation $(>18.6$ versus $\leq 18.6 \%)$ & 0.002 & 10.01 & 2.26 & 44.23 & 0.014 & 9.00 & 1.56 & 52.01 \\
\hline Age $(>71$ yr versus $\leq 71)$ & 0.057 & 2.64 & 0.97 & 7.16 & 0.283 & 1.84 & 0.61 & 5.56 \\
\hline Male sex (versus female) & 0.22 & 2.53 & 0.58 & 11.09 & 0.638 & 1.48 & 0.29 & 7.72 \\
\hline H. pylori infection & 0.263 & 0.55 & 0.19 & 1.57 & 0.046 & 0.21 & 0.04 & 0.97 \\
\hline \multicolumn{9}{|l|}{ Pathological findings in gastric body } \\
\hline Inflammation & 0.167 & 2.23 & 0.72 & 6.92 & 0.007 & 15.71 & 2.11 & 117.09 \\
\hline Activity & 0.863 & 0.92 & 0.34 & 2.45 & 0.076 & 0.31 & 0.09 & 1.13 \\
\hline Atrophy & 0.020 & 4.48 & 1.27 & 15.76 & 0.309 & 2.12 & 0.50 & 9.02 \\
\hline Metaplasia & 0.125 & 2.21 & 0.80 & 6.08 & 0.322 & 1.81 & 0.56 & 5.82 \\
\hline
\end{tabular}

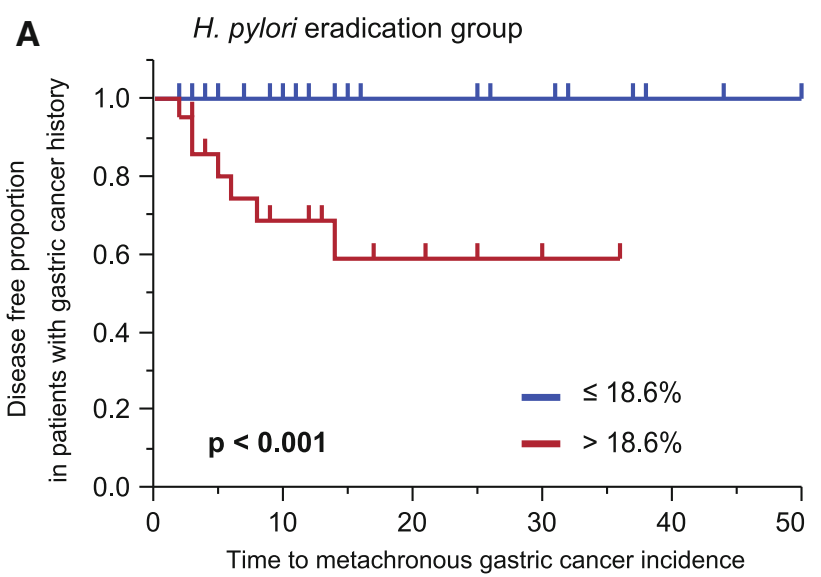

(month)

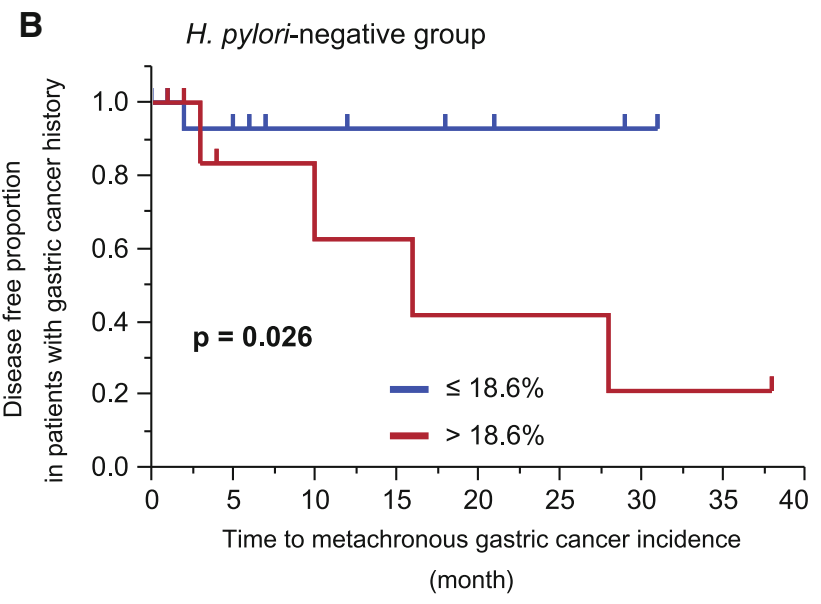

Fig. 3 Association between $m i R-34 b / c$ methylation and metachronous GC risk in $H$. pylori-positive and -negative patients. a KaplanMeier analysis of the effect of $m i R-34 b / c$ methylation on metachronous GC-free survival among $H$. pylori-positive patients who underwent successful eradication after endoscopic treatment of their initial GC $(n=49)$. b Kaplan-Meier analysis of the effect of $m i R$ $34 \mathrm{~b} / \mathrm{c}$ methylation on metachronous GC-free survival among $H$. pylori-negative patients $(n=26)$

\section{Discussion}

Surveillance of patients after ESD has important implications for early detection and treatment of metachronous GC. Although eradication of $H$. pylori can reduce the risk of metachronous GC after endoscopic treatment of the initial GC, it does not ensure complete prevention in all patients [7, 9]. Moreover, current diagnostic tools show patients with past $H$. pylori infections to be $H$. pylorinegative, and they do not receive eradication therapy. Thus, periodic endoscopy is recommended for GC patients after ESD [7]. In an effort to establish a more effective surveillance strategy, we assessed DNA methylation in a set of candidate marker genes in noncancerous gastric mucosa, and then carried out scheduled endoscopic surveillance. This is the first prospective cohort study designed to assess the utility of DNA methylation as a predictive marker of metachronous GC risk.

The evidence collected in various studies to date shows a strong relationship between aberrant methylation of cancer-related genes in noncancerous gastric mucosa and GC risk [16, 22-25]. In addition, genome-wide analyses of DNA methylation using microarray technology has shown that a larger number of genes are methylated in noncancerous gastric mucosa from GC patients than in gastric mucosa from $H$. pylori-positive healthy individuals [26, 27]. In the present study, we focused on $m i R-34 b / c, S F R P$ and $D K K$ family genes, because of the high frequency of their methylation in both GC tissue and adjacent gastric mucosa [17, 20,21]. That $S F R P$ and $D K K$ family genes are frequently methylated in both GC and adjacent gastric mucosa suggests the involvement of an epigenetic field defect $[20,21]$. $m i R-34 b / c$ is a putative tumor suppressor gene that acts as a downstream effector of p53 and is frequently silenced in association with $\mathrm{CpG}$ island hypermethylation in various malignancies [28]. We previously 
showed that levels of $m i R-34 \mathrm{~b} / \mathrm{c}$ methylation in noncancerous gastric mucosa from patients with multiple GCs were significantly higher than in noncancerous gastric mucosa from patients with single GCs or from healthy individuals [17].

We found that methylation of $m i R-34 b / c, S F R P 2$ and $D K K 2$ in the gastric body mucosa was strongly associated with a risk for metachronous GC, and $m i R-34 b / c$ showed the greatest potential to serve as a predictive marker. Multivariate analysis adjusted for age, sex, $H$. pylori status and pathological findings revealed that $m i R-34 b / c$ methylation and inflammation are independently associated with the development of metachronous GC. A number of studies have shown that chronic inflammation is strongly associated with aberrant DNA methylation, and one recent study also showed that the inflammatory response, not $H$. pylori itself, is responsible for the altered DNA methylation in the infected stomach [29, 30]. Consistent with those earlier findings, our study confirms the tight correlation between inflammation and aberrant DNA methylation, and shows that both inflammation and aberrant DNA methylation are independent risk factors of metachronous GC.

It also remains unclear why methylation in the gastric body strongly correlates with increased metachronous GC risk but methylation in the antrum does not. In gastritis patients, the antral mucosa generally exhibits more advanced histological features (e.g., metaplasia and atrophy) than the gastric body mucosa, though inflammation and activity are usually less severe in the antrum [31, 32]. In this study, we observed that methylation of a number of genes was higher in the antrum than in the body (Fig. 2a, Supplementary Figures 1 and 2). In addition, pathological findings in the gastric body mucosa are more likely to reflect the degree and extent of the inflammation and activity of the gastritis than those in the antral mucosa with severe atrophy or metaplasia. An earlier study also showed that individuals with active inflammation in the gastric body (e.g., pangastritis or corpus-predominant gastritis) are at higher risk of developing GC [8]. It is thus conceivable that aberrant methylation in the gastric body is associated an increased risk of metachronous GC.

Interestingly, we found that $m i R-34 b / c$ methylation was also associated with metachronous GC risk in patients who underwent successful $H$. pylori eradication after treatment of their GC. Similarly, while eradication of $H$. pylori after endoscopic resection of early $\mathrm{GC}$ can reduce the risk of metachronous GC risk [9], eradication in patients without a precancerous lesion more effectively reduces the risk of developing $\mathrm{GC}[33,34]$. One possible reason for the development of metachronous GC, even after $H$. pylori eradication, is the presence of malignant cells that cannot be detected through endoscopic exami- nation. In addition, our results suggest that a certain amount of aberrant DNA methylation may not be reversed by eradication, and individuals with high levels of $m i R$ $34 \mathrm{~b} / \mathrm{c}$ methylation may remain at a high risk of metachronous GC.

There are several limitations to this study. First, patient samples were collected at a single institution, and the follow-up period was relatively short (average 18 months). The cumulative incidence rate for metachronous GCs increases linearly with time [7], and we think the incidence of metachronous GCs in our study population would likely increase with a longer follow-up period. Second, the association between $m i R-34 b / c$ methylation and GC risk in healthy individuals remains unclear because we focused on early GC patients who underwent endoscopic treatment. Thus, our findings should be validated in an independent long-term, multicenter study that includes a larger number of patients. Third, our study did not include patients who underwent $H$. pylori eradication therapy prior to their diagnosis. Earlier studies suggest that levels of aberrant methylation in $H$. pylori-infected noncancerous mucosa can be reduced by eradication therapy, but it is unclear how long the effect persists [35-38]. Further studies will be needed to define the relation between $m i R-34 b / c$ methylation and GC risk in patients with history of $H$. pylori eradication therapy.

In summary, we observed that the level of $m i R-34 b / c$ methylation in noncancerous gastric body mucosa is a useful biomarker that is predictive of the risk for metachronous GC risk after endoscopic resection. Thus, for early GC patients with elevated $m i R-34 b / c$ methylation in the gastric body, more intensive and frequent follow-up endoscopy may be recommended after ESD. Our findings may greatly improve of the surveillance strategy used after ESD and contribute to the early detection of metachronous GC and a reduction in its mortality.

Acknowledgments The authors thank Dr. William F. Goldman for editing the manuscript. This study was supported in part by Grants-inAid for Scientific Research (B) from the Japan Society for Promotion of Science (Y. Shinomura), Grants-in-Aid for Young Researchers (B) from the Japan Society for Promotion of Science (E. Yamamoto), a Grant-in-Aid for the Third-term Comprehensive 10-year Strategy for Cancer Control (H. Suzuki), A3 foresight program from the Japan Society for Promotion of Science (H. Suzuki) and the Project for Developing Innovative Research on Cancer Therapeutics (PDIRECT) (H. Suzuki).

Conflict of interest The authors declare that they have no conflict of interest.

Open Access This article is distributed under the terms of the Creative Commons Attribution Noncommercial License which permits any noncommercial use, distribution, and reproduction in any medium, provided the original author(s) and the source are credited. 


\section{References}

1. Ono H, Kondo H, Gotoda T, Shirao K, Yamaguchi H, Saito D, et al. Endoscopic mucosal resection for treatment of early gastric cancer. Gut. 2001;48:225-9.

2. Soetikno R, Kaltenbach T, Yeh R, Gotoda T. Endoscopic mucosal resection for early cancers of the upper gastrointestinal tract. J Clin Oncol. 2005;23:4490-8.

3. Oka S, Tanaka S, Kaneko I, Mouri R, Hirata M, Kawamura T, et al. Advantage of endoscopic submucosal dissection compared with EMR for early gastric cancer. Gastrointest Endosc. 2006;64:877-83.

4. Isomoto H, Shikuwa S, Yamaguchi N, Fukuda E, Ikeda K, Nishiyama $\mathrm{H}$, et al. Endoscopic submucosal dissection for early gastric cancer: a large-scale feasibility study. Gut. 2009;58: 331-6.

5. Nakajima T, Oda I, Gotoda T, Hamanaka H, Eguchi T, Yokoi C, et al. Metachronous gastric cancers after endoscopic resection: how effective is annual endoscopic surveillance? Gastric Cancer. 2006;9:93-8.

6. Maehata Y, Nakamura S, Fujisawa K, Esaki M, Moriyama T, Asano K, et al. Long-term effect of Helicobacter pylori eradication on the development of metachronous gastric cancer after endoscopic resection of early gastric cancer. Gastrointest Endosc. 2012;75:39-46.

7. Kato M, Nishida T, Yamamoto K, Hayashi S, Kitamura S, Yabuta $\mathrm{T}$, et al. Scheduled endoscopic surveillance controls secondary cancer after curative endoscopic resection for early gastric cancer: a multicentre retrospective cohort study by Osaka University ESD study group. Gut. 2012.

8. Uemura N, Okamoto S, Yamamoto S, Matsumura N, Yamaguchi $\mathrm{S}$, Yamakido $\mathrm{M}$, et al. Helicobacter pylori infection and the development of gastric cancer. N Engl J Med. 2001;345:784-9.

9. Fukase K, Kato M, Kikuchi S, Inoue K, Uemura N, Okamoto S, et al. Effect of eradication of Helicobacter pylori on incidence of metachronous gastric carcinoma after endoscopic resection of early gastric cancer: an open-label, randomised controlled trial. Lancet. 2008;372:392-7.

10. Suzuki H, Tokino T, Shinomura Y, Imai K, Toyota M. DNA methylation and cancer pathways in gastrointestinal tumors. Pharmacogenomics. 2008;9:1917-28.

11. Yamamoto E, Suzuki H, Takamaru H, Yamamoto H, Toyota M, Shinomura Y. Role of DNA methylation in the development of diffuse-type gastric cancer. Digestion. 2011;83:241-9.

12. Jones P, Baylin S. The epigenomics of cancer. Cell. 2007;128: 683-92.

13. Maekita T, Nakazawa K, Mihara M, Nakajima T, Yanaoka K, Iguchi M, et al. High levels of aberrant DNA methylation in Helicobacter pylori-infected gastric mucosae and its possible association with gastric cancer risk. Clin Cancer Res. 2006; 12:989-95.

14. Yamamoto E, Toyota M, Suzuki H, Kondo Y, Sanomura T, Murayama Y, et al. LINE-1 hypomethylation is associated with increased $\mathrm{CpG}$ island methylation in Helicobacter pylori-related enlarged-fold gastritis. Cancer Epidemiol Biomarkers Prev. 2008; 17:2555-64.

15. Nakajima $T$, Maekita $T$, Oda $I$, Gotoda $T$, Yamamoto $S$, Umemura $\mathrm{S}$, et al. Higher methylation levels in gastric mucosae significantly correlate with higher risk of gastric cancers. Cancer Epidemiol Biomarkers Prev. 2006;15:2317-21.

16. Ushijima T, Hattori N. Molecular pathways: involvement of Helicobacter pylori-triggered inflammation in the formation of an epigenetic field defect, and its usefulness as cancer risk and exposure markers. Clin Cancer Res. 2012;18:923-9.
17. Suzuki H, Yamamoto E, Nojima M, Kai M, Yamano H, Yoshikawa K, et al. Methylation-associated silencing of microRNA$34 \mathrm{~b} / \mathrm{c}$ in gastric cancer and its involvement in an epigenetic field defect. Carcinogenesis. 2010;31:2066-73.

18. Dixon MF, Genta RM, Yardley JH, Correa P. Classification and grading of gastritis. The updated Sydney system. In: International workshop on the histopathology of gastritis, Houston 1994. Am J Surg Pathol. 1996;20:1161.

19. Toyota M, Suzuki H, Sasaki Y, Maruyama R, Imai K, Shinomura $\mathrm{Y}$, et al. Epigenetic silencing of microRNA-34b/c and B-cell translocation gene 4 is associated with $\mathrm{CpG}$ island methylation in colorectal cancer. Cancer Res. 2008;68:4123-32.

20. Nojima M, Suzuki H, Toyota M, Watanabe Y, Maruyama R, Sasaki S, et al. Frequent epigenetic inactivation of SFRP genes and constitutive activation of wht signaling in gastric cancer. Oncogene. 2007;26:4699-713.

21. Sato H, Suzuki H, Toyota M, Nojima M, Maruyama R, Sasaki S, et al. Frequent epigenetic inactivation of DICKKOPF family genes in human gastrointestinal tumors. Carcinogenesis. 2007;28:2459-66.

22. Chan AO, Lam S, Wong BC, Yuen M, Yeung Y, Hui W, et al. Promoter methylation of E-cadherin gene in gastric mucosa associated with Helicobacter pylori infection and in gastric cancer. Gut. 2003;52:502-6.

23. Cheng ASL, Li M, Kang W, Cheng V, Chou J, Lau S, et al. Helicobacter pylori causes epigenetic dysregulation of FOXD3 to promote gastric carcinogenesis. Gastroenterology. 2013;144:122, 133.e9.

24. Hayashi Y, Tsujii M, Wang J, Kondo J, Akasaka T, Jin Y, et al. CagA mediates epigenetic regulation to attenuate let-7 expression in Helicobacter pylori-related carcinogenesis. Gut. 2012.

25. Ando T, Yoshida T, Enomoto S, Asada K, Tatematsu M, Ichinose $\mathrm{M}$, et al. DNA methylation of microRNA genes in gastric mucosae of gastric cancer patients: its possible involvement in the formation of epigenetic field defect. Int $\mathrm{J}$ Cancer. 2009;124:2367-74.

26. Nanjo S, Asada K, Yamashita S, Nakajima T, Nakazawa K, Maekita T, et al. Identification of gastric cancer risk markers that are informative in individuals with past $H$. pylori infection. Gastric Cancer. 2012;15:382-8.

27. Takamaru H, Yamamoto E, Suzuki H, Nojima M, Maruyama R, Yamano HO, et al. Aberrant methylation of RASGRF1 is associated with an epigenetic field defect and increased risk of gastric cancer. Cancer Prev Res (Phila). 2012;5:1203-12.

28. Suzuki H, Maruyama R, Yamamoto E, Kai M. DNA methylation and microRNA dysregulation in cancer. Mol Oncol. 2012;6: 567-78.

29. Niwa T, Tsukamoto T, Toyoda T, Mori A, Tanaka H, Maekita T, et al. Inflammatory processes triggered by Helicobacter pylori infection cause aberrant DNA methylation in gastric epithelial cells. Cancer Res. 2010;70:1430-40.

30. Chiba T, Marusawa H, Ushijima T. Inflammation-associated cancer development in digestive organs: mechanisms and roles for genetic and epigenetic modulation. Gastroenterology. 2012; 143:550-63.

31. Ikeno T, Ota H, Sugiyama A, Ishida K, Katsuyama T, Genta RM, et al. Helicobacter pylori-induced chronic active gastritis, intestinal metaplasia, and gastric ulcer in Mongolian gerbils. Am J Pathol. 1999;154:951-60.

32. Naylor GM, Gotoda T, Dixon M, Shimoda T, Gatta L, Owen R, et al. Why does Japan have a high incidence of gastric cancer? Comparison of gastritis between UK and Japanese patients. Gut. 2006;55:1545-52.

33. Wong B, Lam S, Wong W, Chen J, Zheng T, Feng R, et al. Helicobacter pylori eradication to prevent gastric cancer in a 
high-risk region of China: a randomized controlled trial. JAMA (Chicago, IL). 2004;291:187-94.

34. Wu CY, Kuo KN, Wu MS, Chen YJ, Wang CB, Lin JT. Early Helicobacter pylori eradication decreases risk of gastric cancer in patients with peptic ulcer disease. Gastroenterology. 2009;137: 1641, 8.e1-2.

35. Chan AO, Peng JZ, Lam SK, Lai KC, Yuen MF, Cheung HK, et al. Eradication of Helicobacter pylori infection reverses E-cadherin promoter hypermethylation. Gut. 2006;55:463-8.

36. Nakajima T, Enomoto S, Yamashita S, Ando T, Nakanishi Y, Nakazawa $\mathrm{K}$, et al. Persistence of a component of DNA methylation in gastric mucosae after Helicobacter pylori eradication. J Gastroenterol. 2010;45:37-44.

37. Perri F, Cotugno R, Piepoli A, Merla A, Quitadamo M, Gentile A, et al. Aberrant DNA methylation in non-neoplastic gastric mucosa of $H$. pylori infected patients and effect of eradication. Am J Gastroenterol. 2007;102:1361-71.

38. Sepulveda A, Yao Y, Yan W, Park D, Kim J, Gooding W, et al. $\mathrm{CpG}$ methylation and reduced expression of O6-methylguanine DNA methyltransferase is associated with Helicobacter pylori infection. Gastroenterology. 2010;138:1836-44. 